\title{
Five years of the Yale Food Addiction Scale: Taking stock and moving forward
}

\author{
Adrian Meule • Ashley N. Gearhardt
}

Published online: 10 May 2014

(C) Springer International Publishing AG 2014

\begin{abstract}
Some forms of overeating show both behavioral and neurobiological similarities to substance use disorders. Accordingly, a possible addiction to food has been discussed for decades, and the debate has received increased scientific and public attention since the beginning of the twenty-first century. In 2009, the Yale Food Addiction Scale (YFAS) was developed in an attempt to provide a standardized self-report instrument for the assessment of food addiction based on the diagnostic criteria for substance dependence. Since then, the YFAS has been used in numerous studies and celebrates its fifth anniversary this year. This article presents an overview of the YFAS and its adaptations, which includes a detailed description of scoring instructions and a supplementary SPSS syntax. Furthermore, psychometric properties and correlates of the YFAS, as well as prevalence rates of food addiction diagnoses and symptoms in different populations, are reviewed. Finally, shortcomings of the scale and future directions for food addiction research and revisions of the YFAS are discussed.
\end{abstract}

Electronic supplementary material The online version of this article (doi:10.1007/s40429-014-0021-z) contains supplementary material, which is available to authorized users.

A. Meule $(\bowtie)$

Institute of Psychology, Department of Psychology I, University of Würzburg, Marcusstr. 9-11, 97070 Würzburg, Germany

e-mail: adrian.meule@uni-wuerzburg.de

\section{A. Meule}

Hospital for Child and Adolescent Psychiatry, LWL University

Hospital of the Ruhr-University Bochum, Hamm, Germany

A. N. Gearhardt

Department of Psychology, University of Michigan, Ann Arbor, MI, USA
Keywords Food addiction · Yale Food Addiction Scale · DSM-IV · DSM-5 · Substance use disorder · Obesity $\cdot$ Binge eating

\section{Introduction}

For decades, researchers have discussed whether some forms of overeating may represent an addictive behavior and if specific foods may have an addictive potential [1]. Although this idea has been sporadically mentioned and investigated in the second half of the twentieth century, scientific as well as public interest in food addiction strongly increased in the 2000s $[2,3]$. This revival of the food addiction concept was partly driven by the pandemic increase of overweight and obesity rates worldwide and neuroimaging studies showing similarities in brain functioning between individuals with obesity and those with substance dependence [4]. These findings were further corroborated by animal models revealing addiction-like behaviors and brain alterations associated with sugar or high-calorie food consumption in rodents $[5,6]$.

However, the concept of food addiction is still a controversial and heavily debated topic [7-12]. Some of the critical remarks, for example, include that although similarities in brain mechanisms of food and drug reward exist, there are also substantial differences [13]. Moreover, it has been argued that human studies on brain mechanisms in obesity or binge eating disorder (BED) are inconsistent [7]. Finally, some researchers disagree about the precise definition of food addiction, and support for the existence of some food addiction symptoms is restricted to animal studies [7, 11]. Unfortunately, objectively measuring food addiction in humans is not an easy task. For example, it is not possible to diagnose people with behavioral or (neuro-)physiological measures due to practical reasons and a lack of established research findings. Instead, interviews or self-report 
questionnaires provide feasible tools to start to identify individuals who may be experiencing an addictive response to food. Using those measures, it can be tested whether these individuals exhibit behavioral, cognitive, and physiological/ neuronal correlates of addiction. Thus, the present article briefly outlines how researchers have attempted to assess food addiction in humans in the past and how it is measured with the Yale Food Addiction Scale (YFAS). Hereinafter, findings from studies in which the YFAS was used are reported and future directions are discussed.

\section{Assessment of Food Addiction}

In early studies on eating behavior from an addiction perspective, the approach for measuring food addiction was rather indirect. In the 1980s, for example, researchers conducted studies on the parallels between substance dependence and bulimia nervosa (BN). Participants completed personality questionnaires such as the MacAndrew Scales or the Eysenck Personality Questionnaire and then scores were compared between individuals with $\mathrm{BN}$ and individuals with substance dependence [14-17]. A lack of differences between groups was interpreted as individuals with $\mathrm{BN}$ having an 'addictive personality'.

A more straightforward approach was chosen in some studies on 'chocolate addiction' in the 1990s. Participants were recruited via advertisements, which asked "are you a chocolate addict?" [18-20]. Obviously, assessment of food addiction based on self-identification is markedly vulnerable to bias. Moreover, validity of such questions is limited by the fact that most nonprofessional participants do not know how addiction is defined.

Hence, a reasonable approach is to ask participants about addiction symptoms as outlined in diagnostic manuals and to classify them as being addicted only when several of those criteria are met. For example, two studies used a structured interview for the assessment of Goodman's Addictive Disorder criteria [21] in individuals with anorexia nervosa (AN), BN, or BED. It was found that between 35 and $48 \%$ of participants with AN or BED, and $65 \%$ of participants with $\mathrm{BN}$, met the full criteria for addictive disorder [22, 23•]. However, a potential downside of using those criteria is that they are quite conservative and that the problematic behavior is not further specified. That is, respondents may misinterpret questions and include behaviors other than eating (e.g., purging). This would also explain why many individuals with $\mathrm{AN}$ met the addictive disorder criteria even though $\mathrm{AN}$ is not related to an increased substance use (i.e., food consumption).

Thus, a more clear-cut procedure is to orient on the diagnostic criteria for substance dependence. Cassin and von Ranson [23•] substituted the references to 'substance' with 'binge eating' in a structured interview on the substance dependence criteria of the Diagnostic and Statistical Manual of Mental Disorders (DSM-IV). Using this interview technique, they found that $92 \%$ of participants with BED met the full criteria for substance dependence. However, the authors also noted that participants' responses may have been influenced by demand characteristics and that reliability and validity of their interview assessment was uncertain [23•].

\section{Yale Food Addiction Scale (YFAS)}

Development, Scoring, and Psychometric Properties

In an attempt to overcome those heterogeneous definitions and measures of food addiction and its symptoms, the YFAS was developed in 2009 in order to provide a standardized assessment tool [24.•]. This 25 -item instrument is based on the seven substance dependence criteria in the DSM-IV (Table 1) and, accordingly, assesses seven food addiction symptoms as well as a clinically significant impairment or distress (Appendix A). Originally, two additional items were included for exploration of the specific kinds of food with which respondents have difficulties controlling consumption. However, these two items have not received much attention in subsequent studies and may be omitted when using the scale. ${ }^{1}$

Participants are instructed to refer to the past 12 months when answering questions. Different response categories are as follows: frequency (e.g., ranging from 'never' to 'four or more times a week or daily') and dichotomous scoring ('yes' or 'no'). Responses are then recoded to all be dichotomous (Appendix A). Three items act as primers for the subsequent items and are not scored. If at least one question of each criterion is scored as one, then this criterion is met. A continuous symptom count can be calculated by adding up the criteria met (except impairment/distress). That is, the symptom count can range between zero and seven symptoms. A dichotomous score can also be calculated: food addiction can be 'diagnosed' when at least three symptoms and the criterion of a clinically significant impairment or distress is met. An SPSS syntax for those calculations can be found in the supplementary material.

The YFAS has a one-factor structure [24••, 25]. KuderRichardson's alpha coefficient is usually reported as an indication of internal consistency because of the different response categories. That is, internal consistency is calculated using the dichotomized item scores (note that SPSS automatically

\footnotetext{
${ }^{1}$ In one study [31], the most often selected foods were chocolate (selected by $54 \%$ of participants), candy (46\%), cookies $(25 \%)$, chips $(25 \%)$, pastries $(21 \%)$, cake $(21 \%)$, pasta $(18 \%)$, pizza $(18 \%)$, ice cream $(16 \%)$, and French fries $(14 \%)$. These foods correspond to the most often craved foods identified in previous studies on food craving [61].
} 
Table 1 Diagnostic criteria of substance use disorder according to the DSM-IV and DSM-5

1. Substance often taken in larger amounts or over a longer period than was intended

2. Persistent desire or unsuccessful efforts to cut down or control substance use

3. Great deal of time is spent in activities necessary to obtain or use the substance or recover from its effects

4. Craving, or a strong desire or urge to use the substance

5. Recurrent substance use resulting in a failure to fulfill major role obligations at work, school, or home

6. Continued use despite having persistent or recurrent social or interpersonal problems caused or exacerbated by the effects of the substance

7. Important social, occupational, or recreational activities are given up or reduced because of substance use

8. Recurrent substance use in situations in which it is physically hazardous

9. Substance use is continued despite knowledge of having a persistent or recurrent physical or psychological problem that is likely to have been caused or exacerbated by the substance

10. Tolerance

a. need for markedly increased amounts of the substance to achieve intoxication or desired effect

b. markedly diminished effect with continued use of the same amount of the substance

11. Withdrawal

a. withdrawal syndrome (differs by substance)

b. substance is taken to relieve or avoid withdrawal symptoms

Criteria printed in boldface are new in DSM-5. Substance use disorder can be diagnosed when a problematic pattern of substance use leads to clinically significant impairment or distress and symptoms occurred within the past 12 months. Severity can be specified as follows: mild (2-3 symptoms), moderate (4-5 symptoms), severe (6 or more symptoms).

DSM-5 Diagnostic and Statistical Manual of Mental Disorders

calculates the Kuder-Richardson coefficient when dichotomous scores are used and 'coefficient alpha' is selected). In the original validation study, internal consistency was $\alpha=0.86$ [24••] and ranged between $\alpha=0.76$ and 0.92 in subsequent studies [26•, 27••, 28-30] (note that differences in internal consistency may emerge across studies if some researchers use all items and others exclude the primer items or the items assessing a clinically significant impairment or distress).

\section{Translations}

The YFAS also is available in German [31]. Its one-factor structure was replicated and internal consistency was comparable to the English version $(\alpha=0.81-0.83[32,31])$. Moreover, validity indices were similar to those reported for the original version, such that medium-to-high positive correlations could be found with the Eating Attitudes Test, and a measure of emotional eating and no or small correlations were found with the Behavioral Inhibition System/Behavioral Activation System [31, 24••]. Factor structure and internal consistency of the German version were further replicated in a sample of obese candidates for bariatric surgery $(\alpha=0.82$ [33]). Finally, a French version of the YFAS was employed in one study and internal consistency was $\alpha=0.90$ [34].

Modified Yale Food Addiction Scale (mYFAS)

Most recently, a short form of the YFAS has been proposed (modified YFAS [mYFAS]) [35•]. It consists of nine items only, with one item for assessing each of the seven symptoms of substance dependence in the DSM-IV and two items assessing the presence of a clinically significant impairment or distress (Appendix B and supplementary material). Internal consistency of the seven questions measuring food addiction symptoms (i.e., without the questions on impairment or distress) ranged between $\alpha=0.75$ and 0.84 . Importantly, the prevalence rates of food addiction diagnoses using the mYFAS, as well as its validity indices, were comparable to those found using the full version [35•].

\section{Yale Food Addiction Scale for Children (YFAS-C)}

A child version of the YFAS (YFAS-C) was recently developed by changing the item wording to be appropriate for children [36]. Specifically, the adult YFAS was altered to refer to age-appropriate activities (e.g., references related to employment were changed to school; parental interactions were included) and the questions were edited to lower the reading level (Flesch-Kincaid reading level=grade 2.7). Response categories were also rephrased to facilitate comprehension (ranging from 'never' to 'always'). Other minor changes included that one item with a dichotomous response format in the adult version was transformed to a continuously scored question, and new scoring thresholds were established (Appendix C and supplementary material). Similar to the adult version, the YFAS-C has a one-factor structure, and internal consistency was $\alpha=0.78$ in the validation study [36].

\section{Prevalence of YFAS Symptoms}

The most common food addiction symptom as assessed with the YFAS is a 'persistent desire or unsuccessful efforts to cut down or control eating' $[35 \cdot, 37]$. Notably, almost $100 \%$ of obese individuals fulfill this criterion [28, 33, 38, 25, 39]. Other commonly endorsed symptoms are 'continued eating despite physical or psychological problems' and 'tolerance', particularly in obese samples $[28,33,38,25,39]$. The remaining symptoms ('consumption of large amounts or over a longer period than intended', 'spending much time obtaining 
food or eating or recover from its effects', 'giving up important activities', and 'withdrawal symptoms') are less common, particularly in nonclinical samples $[35 \bullet, 37]$, but are nonetheless endorsed by a substantial proportion of obese individuals [38, 25, 33, 39].

In a recent study with individuals with $\mathrm{BN}$, the most often endorsed symptom also was 'a persistent desire or unsuccessful efforts to cut down or control eating', corresponding to previous studies. Yet, two other most often endorsed symptoms were 'giving up important activities' and 'withdrawal symptoms', while the least often endorsed symptom was 'tolerance' [40]. A possible explanation for this may simply be an effect of age: samples of obese individuals usually have a higher age than do young women with $\mathrm{BN}$, and development of tolerance may primarily occur after several years of addiction-like eating. Similarly, the most often endorsed food addiction symptoms in children were an 'inability to cut down' and 'giving up important activities' while 'tolerance', 'withdrawal', and 'continued use despite problems' were the least often endorsed symptoms [36].

To conclude, although 'a persistent desire or unsuccessful efforts to cut down or control eating' is the most frequently met food addiction criterion across different studies, endorsement rates of the other food addiction symptoms differ between nonclinical samples, individuals with $\mathrm{BN}$, and obese individuals.

\section{Prevalence of YFAS Diagnoses}

Prevalence rates of food addiction diagnoses according to the YFAS range between approximately 5 and $10 \%$ in student and community samples [24••, 31, 41, 42, 35•, 32]. Similarly, prevalence of food addiction as identified by the YFAS-C was $7 \%$ in children [36]. These numbers need to be interpreted with caution, as food addiction may be overestimated as a result of selection bias, for example, in web-based studies [24••, 31, 32].

Nonetheless, food addiction prevalence is increased in obese samples, ranging between approximately 15 and $25 \%$ $[29,26 \bullet, 27 \bullet \bullet, 28,43]$. Even higher prevalence rates (about $30-50 \%$ ) could be found in morbidly obese bariatric patients or obese individuals with BED [38, 25, 33, 44]. Notably, all participants with current bulimic symptomatology received a YFAS diagnosis in the study described above. However, sample size was small ( $n=26$ [40]).

To conclude, studies using the YFAS have found that about 5-10 \% of participants in primarily nonclinical samples receive a food addiction diagnosis. Prevalence rates are higher in obese samples, and food addiction diagnoses most frequently occur in individuals with binge eating behaviors such as those with BED or BN $[45,46 \bullet]$.

\section{Correlates of YFAS Scores}

\section{Relationships With Body Mass and Weight Change}

As mentioned above, the prevalence of YFAS diagnoses is higher in obese samples than in non-obese samples. However, many studies did not find an association between body mass index (BMI) and YFAS diagnoses or symptoms [29, 27••, 28, $34,26 \bullet, 47 \bullet \bullet, 32,48,49]$. This may be explained by the fact that study samples were restricted to either predominantly normalweight individuals or obese individuals only and that there may be a nonlinear relationship between BMI and food addiction symptomatology [45, 46•]. Specifically, the positive relationship between the YFAS and BMI in non-obese samples may be attenuated by individuals who receive a YFAS diagnosis, but engage in compensatory behaviors. Indeed, even a negative relationship between YFAS symptoms and BMI was found in individuals with $\mathrm{BN}$ [40]. In individuals with morbid obesity, positive relationships between BMI and YFAS scores may be rendered impossible by ceiling effects [46•]. Following this line of thought, positive associations between BMI and YFAS scores may particularly be observed in samples with a wide range in BMI and, indeed, such studies clearly demonstrated a positive relationship $[30,35 \bullet, 41,31]$. In children, the YFAS-C symptom count was also positively related to BMI [36].

Two studies examined whether food addiction symptomatology at baseline is related to treatment success in weight-loss interventions. In one of those studies, YFAS symptoms were negatively correlated with weight loss after 7 weeks of a behavioral weight-loss program, suggesting that food addiction symptomatology may adversely affect treatment success in obese individuals [29]. However, this finding could not be replicated in a more recent study [43]. Future research on the clinical utility of the YFAS is clearly needed. Another gap in the literature is whether individuals with more addictive-like eating are more prone to regain weight following treatment. Further, there has been no examination of how patients with higher YFAS scores respond to treatment for disordered eating or whether the addition of addiction-related treatment techniques (e.g., motivational interviewing, cue-exposure/response-prevention) is helpful for these individuals. This will be an essential future direction for evaluating the usefulness of the YFAS in clinical settings.

\section{Relationships With Other Eating-Related Constructs}

Scores on the YFAS are strongly related to higher eating disorder symptomatology [39, 31, 24••, 44], particularly to binge eating such as in individuals with BED [26•, 38, 25] or BN [40]. Individuals receiving a YFAS diagnosis report experiencing more intense and more frequent food cravings than those who do not receive a YFAS diagnosis [39, 32, 26•].

Moderate-to-large relationships can also be found with other problematic eating behaviors such as emotional eating 
$[31,24 \bullet \bullet, 47 \bullet \bullet, 26 \bullet, 44,29]$. Similarly, the YFAS-C symptom count was positively related to emotional overeating in children [36]. Positive correlations have also been found between YFAS symptoms and scores on the Palatable Eating Motives Scale, which measures eating palatable foods for social reasons and emotion regulation [50].

Positive but weaker associations were observed with external eating behavior $[31,47 \bullet \bullet, 26 \bullet, 40]$, and weak or no relationships have been found with restrained eating $[25,49$, $39,31,38]$. Nevertheless, the number of food addiction symptoms is negatively correlated with perceived self-regulatory success in dieting [51].

One study investigated macronutrient intake in relation to YFAS scores. Participants retrospectively reported their average use of food items in the past 12 months using a food frequency questionnaire. Macronutrient intake was estimated as percent of total calorie intake from those data. Participants with food addiction had higher relative calorie intake from fat and protein, but not carbohydrates, as compared with those with no food addiction [41].

Apart from those findings from questionnaire-based studies, experimental studies on correlates of the YFAS using behavioral or physiological measures are rare. Preliminary evidence in a student sample suggests that women exhibiting signs of food addiction may show an attentional or approach bias towards high-calorie food cues as indicated by accelerated reactions to those stimuli in a go/no-go task [48]. Those results match well with a neuroimaging study showing that food addiction symptoms correlated with elevated activation in reward circuitry in response to an anticipated receipt of food [47••]. Moreover, this study also found that individuals with higher food addiction scores exhibited reduced activation of inhibitory regions in response to food intake [47••]. In a recent study in obese individuals, participants who received a food addiction diagnosis could be distinguished from those not receiving a food addiction diagnosis on a composite genetic index of dopamine signaling. Specifically, food addicted participants had a higher multilocus genetic profile score (reflecting elevated dopamine signaling), and this relationship was mediated by self-reported trait food craving [27••]. Most recently, it could be shown that administration of a dopamine agonist (methylphenidate) differentially affected food consumption in overweight individuals with or without an YFAS diagnosis [52]. Thus, elevated YFAS scores appear to be related to reward-responsive overeating as indicated by self-report as well as neurobiological markers.

\section{Relationships With Other Constructs Not or Indirectly Related} to Eating

In addition to higher eating pathology, food addiction symptomatology is also associated with higher general psychopathology. For instance, individuals with a food addiction diagnosis show higher rates of depression and report higher scores on the Behavioral Inhibition System [31, 24••, 38, 25, $26 \bullet, 28,44,29]$. In obese individuals, higher rates of attentiondeficit hyperactivity disorder have been found in those with a YFAS diagnosis [26•]. In individuals with $\mathrm{BN}$, food addiction symptoms were highly correlated with borderline personality disorder symptomatology [40]. Similarly, food addiction symptoms correlated with lower self-esteem and more difficulties in emotion regulation in individuals with BED $[38,25]$.

A cross-sectional study in which the mYFAS was used found a positive relationship between physical and sexual child abuse severity and the presence of adult food addiction in women [42]. Food addiction symptoms are also correlated with issues related to weight and body image such as more pronounced anti-fat attitudes, higher weight bias internalization, and feelings of shame regarding one's own body [29].

Impulsivity is considered a stable personality trait that represents a risk factor for several mental disorders, for example substance use disorders [53]. Likewise, individuals with food addiction have higher levels of impulsivity as indicated by self-report measures and behavioral tasks such as delay discounting $[31,26 \bullet$, 34]. However, it appears that YFAS scores are particularly associated with specific aspects of impulsivity such as attentional impulsivity [54, 39, 48, 49] as well as urgency and a lack of perseverance [30]. Conversely, YFAS scores seem to be unrelated to other impulsivity-related traits such as sensation or novelty seeking $[34,30]$.

Some studies examined the co-occurrence of food addiction and substance use disorders. In quite a few of them, YFAS scores were unrelated to substance use or substance use disorders [31, 44, 24••, 38, 25]. In a large-scale study in middle-aged and older women, those with food addiction were more likely to be nonsmokers [35•]. Furthermore, those who reported being former smokers were more likely to receive a food addiction diagnosis [35॰]. It may be speculated whether food addiction substitutes or acts as a replacement for tobacco addiction or vice versa. Similarly, gastric bypass patients who had a higher YFAS symptom count before bariatric surgery (based on retrospective reports) were more likely to have post-bariatric substance misuse, suggesting a possible 'addiction transfer' [55]. A recent study reported a trend towards less alcohol use and associated problems in obese individuals with food addiction than in those without food addiction. Importantly, interactive effects between YFAS scores and self-reported impulsivity when predicting problematic alcohol use were found, suggesting that the relationship between substance use and food addiction may be more complex [49]. Specifically, simply looking at co-prevalence data may be insufficient as the association between substance use and food addiction might be influenced by third variables such as impulsivity [56]. 


\section{Summary and Outlook}

Psychometric Properties and Stability

Across different studies, it could be shown that the YFAS has a one-factor structure and adequate internal consistency, which ranges between approximately $\alpha=$ 0.80 and 0.90 . As yet, no study has investigated retestreliability. While most studies that investigate retestreliability of self-report instruments administer the same measure after some weeks, such an approach may be inappropriate for the YFAS, as items refer to the past 12 months in order to correspond to the diagnostic criteria for substance dependence in DSM-IV. Similarly, the timeframe may need to be modified from 12 months to, for example, 1 month (cf. [43]), in order to determine whether the YFAS is sensitive to treatment changes. Preliminary evidence suggests that YFAS scores are decreased after treatment. In a recent study in participants who reported having a history of $\mathrm{BN}$, but did not show signs of current bulimic symptomatology, YFAS diagnoses and symptoms were significantly lower than in participants with current bulimic symptoms [40]. Moreover, prevalence of YFAS diagnoses in 26 obese individuals was $23 \%(n=6)$ after bariatric surgery (A. Meule, unpublished data), which is substantially lower than prevalence rates reported in obese individuals before bariatric surgery [33, 44]. Similarly, prevalence of YFAS diagnoses in 178 obese individuals was $5 \%(n=8)$ at the end of a behavioral weight-loss treatment (M.R. Lent, personal communication), which is lower than prevalence rates reported in obese individuals seeking behavioral weightloss treatment [43, 29].

\section{Correlates and Validity}

Scores on the YFAS are strongly associated with eating pathology, particularly binge eating, as well as with measures of general psychopathology such as depression. As a result, it has been proposed recently that food addiction as measured with the YFAS may merely represent a more severe form of BED [57, 58]. However, this view is challenged by the fact that there are also individuals without BED who receive a YFAS diagnosis $[26 \bullet, 40]$. Nevertheless, the overlap between binge eating and YFAS scores is large, and food addiction appears to be primarily related to binge eating and only secondarily related to higher body mass.

To date, most studies in which the YFAS was used were based on self-report questionnaires only. Thus, there is an urgent need to go beyond cross-sectional, questionnaire-based studies and investigate food addiction in longitudinal or experimental studies. Few investigations exist to show that individuals with or without a YFAS diagnosis (or with a high or low symptom count) can be differentiated by behavioral and brain responses to food cues and a dopaminergic genetic profile, in addition to differences in self-report measures $[48,27 \bullet \bullet, 47 \bullet \bullet$. Yet, sophisticated experimental or field studies are necessary to further support validity of the YFAS. For example, although a substantial proportion of individuals meet the criteria of 'tolerance' and 'withdrawal symptoms' as assessed with the YFAS, other evidence for those symptoms is restricted to animal studies. Elaborated longitudinal studies in which food intake is objectively measured are needed to further support the existence of these symptoms in humans. Other studies may make use of 'ecological momentary assessment' in order to reveal if individuals with a YFAS diagnosis actually spend more 'time in activities necessary to obtain food, eat, and recover from overeating' than do individuals not receiving a YFAS diagnosis.

\section{Adaptations and Future Versions}

Most recently, a short form of the YFAS, the mYFAS, was introduced and it appears that food addiction symptomatology can be assessed sufficiently well with this reduced version. Moreover, a child version of the YFAS, the YFAS-C, was presented, the psychometric properties and validity indices of which were comparable to the adult version. However, all of these versions assess food addiction symptoms based on the substance dependence criteria in the DSM-IV. However, in 2013, a newly revised version of the DSM, the DSM-5, was published that included substantial changes to the substance dependence criteria. Specifically, four criteria were added, including (1) craving, or a strong desire or urge to use the substance; (2) recurrent substance use resulting in a failure to fulfill major role obligations at work, school, or home; (3) continued use despite having persistent or recurrent social or interpersonal problems causes or exacerbated by the effects of the substance; and (4) recurrent substance use in situations in which it is physically hazardous (Table 1).

Future investigations need to determine if and how these new criteria can be translated to eating behavior and whether their application will lead to different prevalence rates and correlates of food addiction [59]. Preliminary evidence based on a qualitative analysis of responses in a semi-structured interview suggest that obese individuals with BED, and to a lesser extent also those without BED, easily fulfill the full criteria for substance use disorder as outlined in the DSM-5 [60•]. Some of the DSM-5 criteria that were previously used to signify substance abuse are highly related to the 
mind altering, intoxicating nature of the substance (e.g., use in physically hazardous situations) and the extent to which they will apply to addictive consumption with little intoxication (as is the case with cigarettes and potentially food) is unclear. Yet, craving was also added to the DSM-5 as an indicator of addiction, and craving for palatable foods has been strongly implicated in binge- and addictive-like eating behavior [26•, 32, 39]. Alterations to the YFAS to reflect changes in the DSM are currently under way (A.N. Gearhardt, unpublished data), and further research will be needed to evaluate this new version.

In conclusion, the development of the YFAS has provided an important measure to evaluate whether an addictive process contributes to certain types of problematic eating behavior. Although the YFAS is not sufficient evidence that 'food addiction' exists, it does provide a standardized tool to identify individuals who are the most likely to be experiencing an addictive response to food. Additionally, the YFAS allows for exploration of the negative consequences that are most commonly related to 'food addiction', such as binge eating and obesity. Finally, the development of the YFAS allows for more rigorous future studies to test the 'food addiction hypothesis' by examining whether the psychological, behavioral, cognitive, and physiological/neural correlates of addiction are also associated with addictive-like eating phenotypes.

\section{Compliance with Ethics Guidelines}

Conflict of Interest Adrian Meule and Ashley N. Gearhardt declare that they have no conflict of interest.

Human and Animal Rights and Informed Consent This article does not contain any studies with human or animal subjects performed by any of the authors.

\section{Appendix A}

Table 2 Items and scoring of the Yale Food Addiction Scale

\begin{tabular}{|c|c|c|c|c|c|c|c|c|}
\hline \multirow{2}{*}{$\begin{array}{l}\text { Item } \\
\text { In the past } 12 \text { months: }\end{array}$} & \multicolumn{5}{|c|}{ Response categories } & \multicolumn{2}{|c|}{ Scoring } & \multirow[t]{2}{*}{ Criterion } \\
\hline & 0 & 1 & 2 & 3 & 4 & 0 & 1 & \\
\hline $\begin{array}{l}\text { 1. I find that when I start } \\
\text { eating certain foods, I } \\
\text { end up eating much } \\
\text { more than planned. }\end{array}$ & never & once a month & $\begin{array}{l}\text { 2-4 times a } \\
\text { month }\end{array}$ & $\begin{array}{l}2-3 \text { times a } \\
\text { week }\end{array}$ & $\begin{array}{l}4 \text { or more times } \\
\text { or daily }\end{array}$ & $0-3$ & 4 & $\begin{array}{l}\text { Substance taken in } \\
\text { larger amount and } \\
\text { for longer period } \\
\text { than intended }\end{array}$ \\
\hline $\begin{array}{l}\text { 2. I find myself continuing } \\
\text { to consume certain } \\
\text { foods even though I } \\
\text { am no longer hungry. }\end{array}$ & never & once a month & $\begin{array}{l}2-4 \text { times a } \\
\text { month }\end{array}$ & $\begin{array}{l}2-3 \text { times a } \\
\text { week }\end{array}$ & $\begin{array}{l}4 \text { or more times } \\
\text { or daily }\end{array}$ & $0-3$ & 4 & $\begin{array}{l}\text { Substance taken in } \\
\text { larger amount and } \\
\text { for longer period } \\
\text { than intended }\end{array}$ \\
\hline $\begin{array}{l}\text { 3. I eat to the point where } \\
\text { I feel physically ill. }\end{array}$ & never & once a month & $\begin{array}{l}\text { 2-4 times a } \\
\text { month }\end{array}$ & $\begin{array}{c}2-3 \text { times a } \\
\text { week }\end{array}$ & $\begin{array}{l}4 \text { or more times } \\
\text { or daily }\end{array}$ & $0-2$ & $3-4$ & $\begin{array}{l}\text { Substance taken in } \\
\text { larger amount and } \\
\text { for longer period } \\
\text { than intended }\end{array}$ \\
\hline $\begin{array}{l}\text { 4. Not eating certain types of } \\
\text { food or cutting down on } \\
\text { certain types of food is } \\
\text { something I worry about. }\end{array}$ & never & once a month & $\begin{array}{l}2-4 \text { times a } \\
\text { month }\end{array}$ & $\begin{array}{l}2-3 \text { times a } \\
\text { week }\end{array}$ & $\begin{array}{l}4 \text { or more times } \\
\text { or daily }\end{array}$ & $0-3$ & 4 & $\begin{array}{l}\text { Persistent desire or } \\
\text { repeated } \\
\text { unsuccessful } \\
\text { attempt to quit }\end{array}$ \\
\hline $\begin{array}{l}\text { 5. I spend a lot of time feeling } \\
\text { sluggish or fatigued from } \\
\text { overeating. }\end{array}$ & never & once a month & $\begin{array}{l}\text { 2-4 times a } \\
\text { month }\end{array}$ & $\begin{array}{l}\text { 2-3 times a } \\
\text { week }\end{array}$ & $\begin{array}{l}4 \text { or more times } \\
\text { or daily }\end{array}$ & $0-2$ & $3-4$ & $\begin{array}{l}\text { Much time/activity to } \\
\text { obtain, use, recover }\end{array}$ \\
\hline $\begin{array}{l}\text { 6. I find myself constantly } \\
\text { eating certain foods } \\
\text { throughout the day. }\end{array}$ & never & once a month & $\begin{array}{l}2-4 \text { times a } \\
\text { month }\end{array}$ & $\begin{array}{l}2-3 \text { times a } \\
\text { week }\end{array}$ & $\begin{array}{l}4 \text { or more times } \\
\text { or daily }\end{array}$ & $0-3$ & 4 & $\begin{array}{l}\text { Much time/activity to } \\
\text { obtain, use, recover }\end{array}$ \\
\hline $\begin{array}{l}\text { 7. I find that when certain } \\
\text { foods are not available, I } \\
\text { will go out of my way to } \\
\text { obtain them. For example, } \\
\text { I will drive to the store } \\
\text { to purchase certain foods }\end{array}$ & never & once a month & $\begin{array}{l}2-4 \text { times a } \\
\text { month }\end{array}$ & $\begin{array}{l}2-3 \text { times a } \\
\text { week }\end{array}$ & $\begin{array}{l}4 \text { or more times } \\
\text { or daily }\end{array}$ & $0-2$ & $3-4$ & $\begin{array}{l}\text { Much time/activity to } \\
\text { obtain, use, recover }\end{array}$ \\
\hline
\end{tabular}


Table 2 (continued)

\begin{tabular}{|c|c|c|c|c|c|c|c|c|}
\hline \multirow{2}{*}{$\begin{array}{l}\text { Item } \\
\text { In the past } 12 \text { months: }\end{array}$} & \multicolumn{5}{|c|}{ Response categories } & \multicolumn{2}{|c|}{ Scoring } & \multirow[t]{2}{*}{ Criterion } \\
\hline & 0 & 1 & 2 & 3 & 4 & 0 & 1 & \\
\hline $\begin{array}{l}\text { options available to me } \\
\text { at home. }\end{array}$ & & & & & & & & \\
\hline $\begin{array}{l}\text { 8. There have been times } \\
\text { when I consumed certain } \\
\text { foods so often or in such } \\
\text { large quantities that I } \\
\text { started to eat food instead } \\
\text { of working, spending time } \\
\text { with my family or friends, } \\
\text { or engaging in other } \\
\text { important activities or } \\
\text { recreational activities } \\
\text { I enjoy. }\end{array}$ & never & once a month & $\begin{array}{l}2-4 \text { times a } \\
\text { month }\end{array}$ & $\begin{array}{l}2-3 \text { times a } \\
\text { week }\end{array}$ & $\begin{array}{l}4 \text { or more times } \\
\text { or daily }\end{array}$ & $0-1$ & $2-4$ & $\begin{array}{l}\text { Important social, } \\
\text { occupational, or } \\
\text { recreational } \\
\text { activities given up } \\
\text { or reduced }\end{array}$ \\
\hline $\begin{array}{l}\text { 9. There have been times } \\
\text { when I consumed certain } \\
\text { foods so often or in such } \\
\text { large quantities that I } \\
\text { spent time dealing with } \\
\text { negative feelings from } \\
\text { overeating instead of } \\
\text { working, spending time } \\
\text { with my family or friends, } \\
\text { or engaging in other } \\
\text { important activities or } \\
\text { recreational activities } \\
\text { I enjoy. }\end{array}$ & never & once a month & $\begin{array}{l}2-4 \text { times a } \\
\text { month }\end{array}$ & $\begin{array}{l}2-3 \text { times a } \\
\text { week }\end{array}$ & $\begin{array}{l}4 \text { or more times } \\
\text { or daily }\end{array}$ & $0-2$ & $3-4$ & $\begin{array}{l}\text { Important social, } \\
\text { occupational, or } \\
\text { recreational } \\
\text { activities given up } \\
\text { or reduced }\end{array}$ \\
\hline $\begin{array}{l}\text { 10. There have been times } \\
\text { when I avoided } \\
\text { professional or social } \\
\text { situations where certain } \\
\text { foods were available, } \\
\text { because I was afraid I } \\
\text { would overeat. }\end{array}$ & never & once a month & $\begin{array}{l}2-4 \text { times a } \\
\text { month }\end{array}$ & $\begin{array}{l}2-3 \text { times a } \\
\text { week }\end{array}$ & $\begin{array}{l}4 \text { or more times } \\
\text { or daily }\end{array}$ & $0-1$ & $2-4$ & $\begin{array}{l}\text { Important social, } \\
\text { occupational, or } \\
\text { recreational } \\
\text { activities given up } \\
\text { or reduced }\end{array}$ \\
\hline $\begin{array}{l}\text { 11. There have been times } \\
\text { when I avoided } \\
\text { professional or social } \\
\text { situations because I was } \\
\text { not able to consume } \\
\text { certain foods there. }\end{array}$ & never & once a month & $\begin{array}{l}2-4 \text { times a } \\
\text { month }\end{array}$ & $\begin{array}{l}2-3 \text { times a } \\
\text { week }\end{array}$ & $\begin{array}{l}4 \text { or more times } \\
\text { or daily }\end{array}$ & $0-1$ & $2-4$ & $\begin{array}{l}\text { Important social, } \\
\text { occupational, or } \\
\text { recreational } \\
\text { activities given up } \\
\text { or reduced }\end{array}$ \\
\hline $\begin{array}{l}\text { 12. I have had withdrawal } \\
\text { symptoms such as } \\
\text { agitation, anxiety, or other } \\
\text { physical symptoms when I } \\
\text { cut down or stopped eating } \\
\text { certain foods. (Please do } \\
\text { NOT include withdrawal } \\
\text { symptoms caused by } \\
\text { cutting down on } \\
\text { caffeinated beverages such } \\
\text { as soda pop, coffee, tea, } \\
\text { energy drinks, etc.) }\end{array}$ & never & once a month & $\begin{array}{l}2-4 \text { times a } \\
\text { month }\end{array}$ & $\begin{array}{l}2-3 \text { times a } \\
\text { week }\end{array}$ & $\begin{array}{l}4 \text { or more times } \\
\text { or daily }\end{array}$ & $0-2$ & $3-4$ & Withdrawal symptoms \\
\hline $\begin{array}{l}\text { 13. I have consumed certain } \\
\text { foods to prevent feelings of } \\
\text { anxiety, agitation, or other } \\
\text { physical symptoms that } \\
\text { were developing. (Please } \\
\text { do NOT include } \\
\text { consumption of caffeinated } \\
\text { beverages such as soda } \\
\text { pop, coffee, tea, energy } \\
\text { drinks, etc.) }\end{array}$ & never & once a month & $\begin{array}{l}\text { 2-4 times a } \\
\text { month }\end{array}$ & $\begin{array}{l}2-3 \text { times a } \\
\text { week }\end{array}$ & $\begin{array}{l}4 \text { or more times } \\
\text { or daily }\end{array}$ & $0-2$ & $3-4$ & Withdrawal symptoms \\
\hline $\begin{array}{l}\text { 14. I have found that I have } \\
\text { elevated desire for or urges }\end{array}$ & never & once a month & $\begin{array}{l}2-4 \text { times a } \\
\text { month }\end{array}$ & $\begin{array}{l}2-3 \text { times a } \\
\text { week }\end{array}$ & $\begin{array}{l}4 \text { or more times } \\
\text { or daily }\end{array}$ & $0-2$ & $3-4$ & Withdrawal symptoms \\
\hline
\end{tabular}


Table 2 (continued)

\begin{tabular}{|c|c|c|c|c|c|c|c|c|}
\hline \multirow{2}{*}{$\begin{array}{l}\text { Item } \\
\text { In the past } 12 \text { months: }\end{array}$} & \multicolumn{5}{|c|}{ Response categories } & \multicolumn{2}{|c|}{ Scoring } & \multirow[t]{2}{*}{ Criterion } \\
\hline & 0 & 1 & 2 & 3 & 4 & 0 & 1 & \\
\hline \multicolumn{9}{|l|}{$\begin{array}{l}\text { when I cut down or stop } \\
\text { eating them. }\end{array}$} \\
\hline $\begin{array}{l}\text { 15. My behavior with respect } \\
\text { to food and eating causes } \\
\text { significant distress. }\end{array}$ & never & once a month & $\begin{array}{l}\text { 2-4 times a } \\
\text { month }\end{array}$ & $\begin{array}{l}2-3 \text { times a } \\
\text { week }\end{array}$ & $\begin{array}{l}4 \text { or more times } \\
\text { or daily }\end{array}$ & $0-2$ & $3-4$ & $\begin{array}{l}\text { Use causes clinically } \\
\text { significant } \\
\text { impairment or } \\
\text { distress }\end{array}$ \\
\hline $\begin{array}{l}\text { 16. I experience significant } \\
\text { problems in my ability to } \\
\text { function effectively (daily } \\
\text { routine, job/school, social } \\
\text { activities, family activities, } \\
\text { health difficulties) because } \\
\text { of food and eating. }\end{array}$ & never & once a month & $\begin{array}{l}\text { 2-4 times a } \\
\text { month }\end{array}$ & $\begin{array}{l}2-3 \text { times a } \\
\text { week }\end{array}$ & $\begin{array}{l}4 \text { or more times } \\
\text { or daily }\end{array}$ & $0-2$ & $3-4$ & $\begin{array}{l}\text { Use causes clinically } \\
\text { significant } \\
\text { impairment or } \\
\text { distress }\end{array}$ \\
\hline $\begin{array}{l}\text { 17. My food consumption } \\
\text { has caused significant } \\
\text { psychological problems } \\
\text { such as depression, } \\
\text { anxiety, self-loathing, } \\
\text { or guilt. }\end{array}$ & no & yes & - & - & - & - & - & (primer) \\
\hline $\begin{array}{l}\text { 18. My food consumption has } \\
\text { caused significant physical } \\
\text { problems or made a } \\
\text { physical problem worse. }\end{array}$ & no & yes & - & - & - & - & - & (primer) \\
\hline $\begin{array}{l}\text { 19. I kept consuming the same } \\
\text { types of food or the same } \\
\text { amount of food even } \\
\text { though I was having } \\
\text { emotional and/or physical } \\
\text { problems. }\end{array}$ & no & yes & - & - & - & 0 & 1 & $\begin{array}{l}\text { Use continues despite } \\
\text { knowledge of } \\
\text { adverse } \\
\text { consequences }\end{array}$ \\
\hline $\begin{array}{l}\text { 20. Over time, I have found } \\
\text { that I need to eat more and } \\
\text { more to get the feeling I } \\
\text { want, such as reduced } \\
\text { negative emotions or } \\
\text { increased pleasure. }\end{array}$ & no & yes & - & - & - & 0 & 1 & Tolerance \\
\hline $\begin{array}{l}\text { 21. I have found that eating } \\
\text { the same amount of food } \\
\text { does not reduce my } \\
\text { negative emotions or } \\
\text { increase pleasurable } \\
\text { feelings the way it used to. }\end{array}$ & no & yes & - & - & - & 0 & 1 & Tolerance \\
\hline $\begin{array}{l}\text { 22. I want to cut down or stop } \\
\text { eating certain kinds of } \\
\text { food. }\end{array}$ & no & yes & - & - & - & 0 & 1 & $\begin{array}{l}\text { Persistent desire or } \\
\text { repeated } \\
\text { unsuccessful } \\
\text { attempt to quit }\end{array}$ \\
\hline $\begin{array}{l}\text { 23. I have tried to cut down or } \\
\text { stop eating certain kinds of } \\
\text { food. }\end{array}$ & no & yes & - & - & - & - & - & (primer) \\
\hline $\begin{array}{l}\text { 24. I have been successful at } \\
\text { cutting down or not eating } \\
\text { these kinds of food. }\end{array}$ & no & yes & - & - & - & 1 & 0 & $\begin{array}{l}\text { Persistent desire or } \\
\text { repeated } \\
\text { unsuccessful } \\
\text { attempt to quit }\end{array}$ \\
\hline $\begin{array}{l}\text { 25. How many times in the } \\
\text { past year did you try to cut } \\
\text { down or stop eating certain } \\
\text { foods altogether? }\end{array}$ & 1 time & 2 times & 3 times & 4 times & 5 or more times & $0-3$ & 4 & $\begin{array}{l}\text { Persistent desire or } \\
\text { repeated } \\
\text { unsuccessful } \\
\text { attempt to quit }\end{array}$ \\
\hline
\end{tabular}

Notes. If at least one question of each criterion is scored as one, then this criterion is met. A continuous symptom count can be calculated by adding up the criteria met (except impairment/distress). That is, the symptom count can range between zero and seven symptoms. A dichotomous score can also be calculated. Food addiction can be 'diagnosed' when at least three symptoms and the criterion of a clinically significant impairment or distress is met. 


\section{Appendix B}

Table 3 Items and scoring of the modified Yale Food Addiction Scale

\begin{tabular}{|c|c|c|c|c|c|c|c|c|}
\hline \multirow{2}{*}{$\begin{array}{l}\text { Item } \\
\text { In the past } 12 \text { months: }\end{array}$} & \multicolumn{5}{|c|}{ Response categories } & \multicolumn{2}{|c|}{ Scoring } & \multirow[t]{2}{*}{ Criterion } \\
\hline & 0 & 1 & 2 & 3 & 4 & 0 & 1 & \\
\hline $\begin{array}{l}\text { 1. I find myself consuming } \\
\text { certain foods even though } \\
\text { I am no longer hungry. }\end{array}$ & never & once a month & 2-4 times a month & 2-3 times a week & $\begin{array}{l}4 \text { or more times } \\
\text { or daily }\end{array}$ & $0-3$ & 4 & $\begin{array}{l}\text { Substance taken in } \\
\text { larger amount and for } \\
\text { longer period than } \\
\text { intended }\end{array}$ \\
\hline $\begin{array}{l}\text { 2. I worry about cutting } \\
\text { down on certain foods. }\end{array}$ & never & once a month & 2-4 times a month & 2-3 times a week & $\begin{array}{l}4 \text { or more times } \\
\text { or daily }\end{array}$ & $0-3$ & 4 & $\begin{array}{l}\text { Persistent desire or } \\
\text { repeated unsuccessful } \\
\text { attempt to quit }\end{array}$ \\
\hline $\begin{array}{l}\text { 3. I feel sluggish or fatigued } \\
\text { from overeating. }\end{array}$ & never & once a month & 2-4 times a month & 2-3 times a week & $\begin{array}{l}4 \text { or more times } \\
\text { or daily }\end{array}$ & $0-2$ & $3-4$ & $\begin{array}{l}\text { Much time/activity to } \\
\text { obtain, use, recover }\end{array}$ \\
\hline $\begin{array}{l}\text { 4. I have spent time dealing } \\
\text { with negative feelings from } \\
\text { overeating certain foods, } \\
\text { instead of spending time in } \\
\text { important activities such as } \\
\text { time with family, friends, } \\
\text { work, or recreation. }\end{array}$ & never & once a month & 2-4 times a month & 2-3 times a week & $\begin{array}{l}4 \text { or more times } \\
\text { or daily }\end{array}$ & $0-2$ & $3-4$ & $\begin{array}{l}\text { Important social, } \\
\text { occupational, or } \\
\text { recreational activities } \\
\text { given up or reduced }\end{array}$ \\
\hline $\begin{array}{l}\text { 5. I have had physical } \\
\text { withdrawal symptoms } \\
\text { such as agitation and } \\
\text { anxiety when I cut } \\
\text { down on certain foods. } \\
\text { (Do NOT include } \\
\text { caffeinated drinks: } \\
\text { coffee, tea, cola, } \\
\text { energy drinks, etc.) }\end{array}$ & never & once a month & 2-4 times a month & 2-3 times a week & $\begin{array}{l}4 \text { or more times } \\
\text { or daily }\end{array}$ & $0-2$ & $3-4$ & Withdrawal symptoms \\
\hline $\begin{array}{l}\text { 6. I kept consuming the same } \\
\text { types or amounts of food } \\
\text { despite significant emotional } \\
\text { and/or physical problems } \\
\text { related to my eating. }\end{array}$ & no & yes & - & - & - & 0 & 1 & $\begin{array}{l}\text { Use continues despite } \\
\text { knowledge of } \\
\text { adverse consequences }\end{array}$ \\
\hline $\begin{array}{l}\text { 7. Eating the same amount } \\
\text { of food does not reduce } \\
\text { negative emotions or } \\
\text { increase pleasurable } \\
\text { feelings the way it used to. }\end{array}$ & no & yes & - & - & - & 0 & 1 & Tolerance \\
\hline $\begin{array}{l}\text { 8. My behavior with respect } \\
\text { to food and eating causes } \\
\text { significant distress. }\end{array}$ & never & once a month & 2-4 times a month & 2-3 times a week & $\begin{array}{l}4 \text { or more times } \\
\text { or daily }\end{array}$ & $0-2$ & $3-4$ & $\begin{array}{l}\text { Use causes clinically } \\
\text { significant impairment } \\
\text { or distress }\end{array}$ \\
\hline $\begin{array}{l}\text { 9. I experience significant } \\
\text { problems in my ability to } \\
\text { function effectively (daily } \\
\text { routine, job/school, social } \\
\text { activities, family activities, } \\
\text { health difficulties) because } \\
\text { of food and eating. }\end{array}$ & never & once a month & 2-4 times a month & 2-3 times a week & $\begin{array}{l}4 \text { or more times } \\
\text { or daily }\end{array}$ & $0-2$ & $3-4$ & $\begin{array}{l}\text { Use causes clinically } \\
\text { significant impairment } \\
\text { or distress }\end{array}$ \\
\hline
\end{tabular}

Notes. If at least one question of each criterion is scored as one, then this criterion is met. A continuous symptom count can be calculated by adding up the criteria met (except impairment/distress). That is, the symptom count can range between zero and seven symptoms. A dichotomous score can also be calculated. Food addiction can be 'diagnosed' when at least three symptoms and the criterion of a clinically significant impairment or distress is met. 


\section{Appendix C}

Table 4 Items and scoring of the Yale Food Addiction Scale for children

\begin{tabular}{|c|c|c|c|c|c|c|c|c|}
\hline \multirow{2}{*}{$\begin{array}{l}\text { Item } \\
\text { In the last year (past } 12 \text { months): }\end{array}$} & \multicolumn{5}{|c|}{ Response categories } & \multicolumn{2}{|c|}{ Scoring } & \multirow[t]{2}{*}{ Criterion } \\
\hline & 0 & 1 & 2 & 3 & 4 & 0 & 1 & \\
\hline $\begin{array}{l}\text { 1. When I start eating, I find } \\
\text { it hard to stop. }\end{array}$ & never & rarely & sometimes & very often & always & $0-2$ & $3-4$ & $\begin{array}{l}\text { Substance taken in larger } \\
\text { amount and for longer } \\
\text { period than intended }\end{array}$ \\
\hline $\begin{array}{l}\text { 2. I eat food even when I am } \\
\text { not hungry. }\end{array}$ & never & rarely & sometimes & very often & always & $0-3$ & 4 & $\begin{array}{l}\text { Substance taken in larger } \\
\text { amount and for longer } \\
\text { period than intended }\end{array}$ \\
\hline $\begin{array}{l}\text { 3. I eat until my stomach hurts } \\
\text { or I feel sick. }\end{array}$ & never & rarely & sometimes & very often & always & $0-2$ & $3-4$ & $\begin{array}{l}\text { Substance taken in larger } \\
\text { amount and for longer } \\
\text { period than intended }\end{array}$ \\
\hline $\begin{array}{l}\text { 4. I worry about eating too } \\
\text { much food. }\end{array}$ & never & rarely & sometimes & very often & always & $0-3$ & 4 & $\begin{array}{l}\text { Persistent desire or repeated } \\
\text { unsuccessful attempt to quit }\end{array}$ \\
\hline $\begin{array}{l}\text { 5. I feel tired a lot because I } \\
\text { eat too much. }\end{array}$ & never & rarely & sometimes & very often & always & $0-2$ & $3-4$ & $\begin{array}{l}\text { Much time/activity to obtain, } \\
\text { use, recover }\end{array}$ \\
\hline 6. I eat food all day long. & never & rarely & sometimes & very often & always & $0-3$ & 4 & $\begin{array}{l}\text { Much time/activity to obtain, } \\
\text { use, recover }\end{array}$ \\
\hline $\begin{array}{l}\text { 7. If I cannot find a food I want, } \\
\text { I will try hard to get it (ex. }\end{array}$ & never & rarely & sometimes & very often & always & $0-2$ & $3-4$ & $\begin{array}{l}\text { Much time/activity to obtain, } \\
\text { use, recover }\end{array}$ \\
\hline
\end{tabular}

ask a friend to get it for me,

find a vending machine,

sneak food when people

aren't looking).

8. I eat food rather than do other things I like (ex. play, hang out with friends).

9. I eat so much that I feel bad afterwards. I feel so bad that I do not do things I like (ex. play, hang out with friends).

10. I avoid places that have a lot of food, because I might eat too much.

11. I avoid places where I cannot eat the food I want.

\begin{tabular}{|c|c|c|c|c|c|c|c|}
\hline never & rarely & sometimes & very often & always & $0-2$ & $3-4$ & $\begin{array}{l}\text { Important social, occupational, } \\
\text { or recreational activities } \\
\text { given up or reduced }\end{array}$ \\
\hline never & rarely & sometimes & very often & always & $0-2$ & $3-4$ & $\begin{array}{l}\text { Important social, occupational, } \\
\text { or recreational activities } \\
\text { given up or reduced }\end{array}$ \\
\hline never & rarely & sometimes & very often & always & $0-2$ & $3-4$ & $\begin{array}{l}\text { Important social, occupational, } \\
\text { or recreational activities } \\
\text { given up or reduced }\end{array}$ \\
\hline never & rarely & sometimes & very often & always & $0-1$ & $2-4$ & $\begin{array}{l}\text { Important social, occupational, } \\
\text { or recreational activities } \\
\text { given up or reduced }\end{array}$ \\
\hline never & rarely & sometimes & very often & always & $0-2$ & $3-4$ & Withdrawal symptoms \\
\hline never & rarely & sometimes & very often & always & $0-2$ & $3-4$ & Withdrawal symptoms \\
\hline never & rarely & sometimes & very often & always & $0-2$ & $3-4$ & Withdrawal symptoms \\
\hline never & rarely & sometimes & very often & always & $0-2$ & $3-4$ & $\begin{array}{l}\text { Use causes clinically } \\
\text { significant impairment } \\
\text { or distress }\end{array}$ \\
\hline never & rarely & sometimes & very often & always & $0-2$ & $3-4$ & $\begin{array}{l}\text { Use causes clinically } \\
\text { significant impairment } \\
\text { or distress }\end{array}$ \\
\hline never & rarely & sometimes & very often & always & $0-3$ & 4 & $\begin{array}{l}\text { Persistent desire or repeated } \\
\text { unsuccessful attempt to quit }\end{array}$ \\
\hline never & rarely & sometimes & very often & always & $0-3$ & 4 & $\begin{array}{l}\text { Persistent desire or repeated } \\
\text { unsuccessful attempt to quit }\end{array}$ \\
\hline no & yes & - & - & - & - & - & (primer) \\
\hline no & yes & - & - & - & - & - & (primer) \\
\hline
\end{tabular}

12. When I do not eat certain foods, I feel upset or sick.

13. I eat certain foods to stop from feeling upset or sick.

14. When I cut down or stop eating certain foods, I crave them a lot more.

15. The way I eat makes me really unhappy.

16. The way I eat causes me problems. (ex. problems at school, with my parents, with my friends).

17. I want to cut down or stop eating certain foods.

18. How often do you try to cut down on certain foods?

19. The way I eat has made me feel sad, nervous, or guilty.

20. The way I eat has made me unhealthy. 
Table 4 (continued)

\begin{tabular}{|c|c|c|c|c|c|c|c|c|}
\hline \multirow{2}{*}{$\begin{array}{l}\text { Item } \\
\text { In the last year (past } 12 \text { months): }\end{array}$} & \multicolumn{5}{|c|}{ Response categories } & \multicolumn{2}{|c|}{ Scoring } & \multirow[t]{2}{*}{ Criterion } \\
\hline & 0 & 1 & 2 & 3 & 4 & 0 & 1 & \\
\hline $\begin{array}{l}\text { 21. I eat in the same way even } \\
\text { though it is causing problems. }\end{array}$ & no & yes & - & - & - & 0 & 1 & $\begin{array}{l}\text { Use continues despite } \\
\text { knowledge of adverse } \\
\text { consequences }\end{array}$ \\
\hline $\begin{array}{l}\text { 22. I need to eat more to get the } \\
\text { good feelings I want. (ex. feel } \\
\text { happy, calm, relaxed) }\end{array}$ & no & yes & - & - & - & 0 & 1 & Tolerance \\
\hline $\begin{array}{l}\text { 23. When I eat the same amount } \\
\text { of food, I do not feel good } \\
\text { the way I used to. (ex. feel } \\
\text { happy, calm, relaxed) }\end{array}$ & no & yes & - & - & - & 0 & 1 & Tolerance \\
\hline $\begin{array}{l}\text { 24. I try to cut down or stop } \\
\text { eating certain foods. }\end{array}$ & no & yes & - & - & - & - & - & (primer) \\
\hline $\begin{array}{l}\text { 25. I am able to cut down } \\
\text { on certain foods. }\end{array}$ & no & yes & - & - & - & 1 & 0 & $\begin{array}{l}\text { Persistent desire or repeated } \\
\text { unsuccessful attempt to quit }\end{array}$ \\
\hline
\end{tabular}

Notes. If at least one question of each criterion is scored as one, then this criterion is met. A continuous symptom count can be calculated by adding up the criteria met (except impairment/distress). That is, the symptom count can range between zero and seven symptoms. A dichotomous score can also be calculated. Food addiction can be 'diagnosed' when at least three symptoms and the criterion of a clinically significant impairment or distress is met

\section{References}

Papers of particular interest, published recently, have been highlighted as:

- Of importance

-. Of major importance

1. Randolph TG. The descriptive features of food addiction: addictive eating and drinking. Q J Stud Alcohol. 1956;17:198-224.

2. Gearhardt AN, Davis C, Kuschner R, Brownell KD. The addiction potential of hyperpalatable foods. Curr Drug Abus Rev. 2011;4: $140-5$.

3. Davis C, Carter JC. Compulsive overeating as an addiction disorder. A review of theory and evidence. Appetite. 2009;53:1-8.

4. Volkow ND, Wise RA. How can drug addiction help us understand obesity? Nat Neurosci. 2005;8:555-60.

5. Avena NM, Rada P, Hoebel BG. Evidence for sugar addiction: behavioral and neurochemical effects of intermittent, excessive sugar intake. Neurosci Biobehav Rev. 2008;32:20-39.

6. Johnson PM, Kenny PJ. Dopamine D2 receptors in addiction-like reward dysfunction and compulsive eating in obese rats. Nat Neurosci. 2010;13:635-41.

7. Ziauddeen H, Farooqi IS, Fletcher PC. Obesity and the brain: how convincing is the addiction model? Nat Rev Neurosci. 2012;13: 279-86.

8. Ziauddeen H, Farooqi IS, Fletcher PC. Food addiction: is there a baby in the bathwater? Nat Rev Neurosci. 2012;13:514.

9. Ziauddeen H, Fletcher PC. Is food addiction a valid and useful concept? Obes Rev. 2013;14:19-28.

10. Avena NM, Gearhardt AN, Gold MS, Wang G-J, Potenza MN. Tossing the baby out with the bathwater after a brief rinse? The potential downside of dismissing food addiction based on limited data. Nat Rev Neurosci. 2012;13:514.

11. Meule A, Kübler A. The translation of substance dependence criteria to food-related behaviors: different views and interpretations. Front Psychiatry. 2012;3(64):1-2.

12. Meule A. Are certain foods addictive? Front Psychiatry. 2014;5(38): $1-3$.
13. Benton $\mathrm{D}$. The plausibility of sugar addiction and its role in obesity and eating disorders. Clin Nutr. 2010;29:288-303.

14. de Silva P, Eysenck S. Personality and addictiveness in anorexic and bulimic patients. Personal Individ Differ. 1987;8:749-51.

15. Feldman J, Eysenck S. Addictive personality traits in bulimic patients. Personal Individ Differ. 1986;7:923-6.

16. Hatsukami D, Owen P, Pyle R, Mitchell J. Similarities and differences on the MMPI between women with bulimia and women with alcohol or drug abuse problems. Addict Behav. 1982;7:435-9.

17. Kagan DM, Albertson LM. Scores on MacAndrew Factors: bulimics and other addictive populations. Int J Eat Disord. 1986;5: $1095-101$.

18. Hetherington MM, Macdiarmid JI. "Chocolate addiction": a preliminary study of its description and its relationship to problem eating. Appetite. 1993;21:233-46.

19. Macdiarmid JI, Hetherington MM. Mood modulation by food: an exploration of affect and cravings in 'chocolate addicts'. Br J Clin Psychol. 1995;34:129-38.

20. Tuomisto T, Hetherington MM, Morris M-F, Tuomisto MT, Turjanmaa V, Lappalainen R. Psychological and physiological characteristics of sweet food "addiction". Int J Eat Disord. 1999;25:169-75.

21. Goodman A. Addiction: definition and implications. Br J Addict. 1990;85:1403-8.

22. Speranza M, Revah-Levy A, Giquel L, Loas G, Venisse J-L, Jeammet $\mathrm{P}$, et al. An investigation of Goodman's addictive disorder criteria in eating disorders. Eur Eat Disord Rev. 2012;20:1829.

23. Cassin SE, von Ranson KM. Is binge eating experienced as an addiction? Appetite. 2007;49:687-90. This was the first study in which a structured clinical interview was used to assess food addiction symptoms. Using this technique, it could be shown that almost all participants with binge eating disorder met full criteria for substance dependence based on the DSM-IV.

24.• Gearhardt AN, Corbin WR, Brownell KD. Preliminary validation of the Yale Food Addiction Scale. Appetite. 2009;52:430-6. In this article, the original version of the YFAS was presented and validated in a student sample.

25. Gearhardt AN, White MA, Masheb RM, Morgan PT, Crosby RD, Grilo CM. An examination of the food addiction construct in obese 
patients with binge eating disorder. Int J Eat Disord. 2012;45: 657-63.

26. Davis C, Curtis C, Levitan RD, Carter JC, Kaplan AS, Kennedy JL. Evidence that 'food addiction' is a valid phenotype of obesity. Appetite. 2011;57:711-7. This was the first study showing that food addicted and nonaddicted obese individuals (based on the YFAS) can be differentiated on a range of psychopathological and eating-related measures as well as behavioral measures assessing impulsivity.

27.• Davis C, Loxton NJ, Levitan RD, Kaplan AS, Carter JC, Kennedy JL. 'Food addiction' and its association with a dopaminergic multilocus genetic profile. Physiol Behav. 2013;118:63-9. This was the first study showing that food addicted and nonaddicted obese individuals (based on the YFAS) differed on a multilocus genetic profile indicating higher dopamine signaling in those with food addiction. Moreover, this relationship was mediated by frequent experiences of food cravings. Thus, results showed that food addiction is related to reward-responsive overeating as indicated by both self-report measures and biological markers.

28. Eichen DM, Lent MR, Goldbacher E, Foster GD. Exploration of "food addiction" in overweight and obese treatment-seeking adults. Appetite. 2013;67:22-4.

29. Burmeister JM, Hinman N, Koball A, Hoffmann DA, Carels RA. Food addiction in adults seeking weight loss treatment. Implications for psychosocial health and weight loss. Appetite. 2013;60:103-10.

30. Murphy CM, Stojek MK, MacKillop J. Interrelationships among impulsive personality traits, food addiction, and body mass index. Appetite. 2014;73:45-50.

31. Meule A, Vögele C. Kübler A [German translation and validation of the Yale Food Addiction Scale]. Diagnostica. 2012;58:115-26.

32. Meule A, Kübler A. Food cravings in food addiction: the distinct role of positive reinforcement. Eat Behav. 2012;13:252-5.

33. Meule A, Heckel D, Kübler A. Factor structure and item analysis of the Yale Food Addiction Scale in obese candidates for bariatric surgery. Eur Eat Disord Rev. 2012;20:419-22.

34. Bégin C, St-Louis M-E, Turmel S, Tousignant B, Marion L-P, Ferland F, et al. Does food addiction distinguish a specific subgroup of overweight/obese overeating women? Health. 2012;4:1492-9.

35. Flint AJ, Gearhardt AN, Corbin WR, Brownell KD, Field AE, Rimm EB. Food addiction scale measurement in 2 cohorts of middle-aged and older women. Am J Clin Nutr. 2014;99(3):578-86. This was the first large-scale study in which the YFAS was used, providing information about the prevalence of food addiction and associations with, for example, body mass index and smoking behavior.

36. Gearhardt AN, Roberto CA, Seamans MJ, Corbin WR, Brownell KD. Preliminary validation of the Yale Food Addiction Scale for children. Eat Behav. 2013;14:508-12.

37. Gearhardt AN, Corbin WR, Brownell KD. Instruction sheet for the Yale Food Addiction Scale. Available from: http:// wwwyaleruddcenter.org/resources/upload/docs/what/addiction/ FoodAddictionScaleInstructions09.pdf. 2008.

38. Gearhardt AN, White MA, Masheb RM, Grilo CM. An examination of food addiction in a racially diverse sample of obese patients with binge eating disorder in primary care settings. Compr Psychiatry. 2013;54:500-5.

39. Meule A, Hermann T, Kübler A. Food addiction in overweight and obese adolescents seeking weight-loss treatment. Adipositas. 2013;7:A48.

40. Meule A, von Rezori V, Blechert J. Food addiction and bulimia nervosa. in revision.

41. Pedram P, Wadden D, Amini P, Gulliver W, Randell E, Cahill F, et al. Food addiction: its prevalence and significant association with obesity in the general population. PLoS One. 2013;8(e74832):1-6.

42. Mason SM, Flint AJ, Field AE, Austin SB, Rich-Edwards JW. Abuse victimization in childhood or adolescence and risk of food addiction in adult women. Obesity. 2013;21:E775-81.
43. Lent MR, Eichen DM, Goldbacher E, Wadden TA, Foster GD. Relationship of food addiction to weight loss and attrition during obesity treatment. Obesity. 2014;22:52-5.

44. Clark SM, Saules KK. Validation of the Yale Food Addiction Scale among a weight-loss surgery population. Eat Behav. 2013;14:216-9.

45. Meule A. How prevalent is "food addiction"? Front Psychiatry. 2011;2(61):1-4.

46. Meule A. Food addiction and body-mass-index: a non-linear relationship. Med Hypotheses. 2012;79:508-11. This article reviews the prevalence of food addiction (as measured with the YFAS) and of binge eating behavior as a function of body mass. It suggests that there may be a nonlinear relationship between food addiction and body mass, which would explain why positive relationships between the YFAS and BMI can primarily be observed in samples with a wide range in body mass, but not in samples with a restricted range in body mass.

47.• Gearhardt AN, Yokum S, Orr PT, Stice E, Corbin WR, Brownell KD. Neural correlates of food addiction. Arch Gen Psychiatry. 2011;68:808-16. This was the first study in which brain activity in anticipation of and in response to food intake was examined as a function of scores on the YFAS. Distinct associations between food addiction symptomatology and neural responses in reward-related and inhibitory regions could be found.

48. Meule A, Lutz A, Vögele C, Kübler A. Women with elevated food addiction symptoms show accelerated reactions, but no impaired inhibitory control, in response to pictures of high-calorie food-cues. Eat Behav. 2012;13:423-8.

49. Meule A, Heckel D, Jurowich CF, Vögele C, Kübler A. Correlates of food addiction in obese individuals seeking bariatric surgery. in revision.

50. Burgess EE, Turan B, Lokken KL, Morse A, Boggiano MM. Profiling motives behind hedonic eating. Preliminary validation of the Palatable Eating Motives Scale. Appetite. 2014;72:66-72.

51. Meule A, Papies EK, Kübler A. Differentiating between successful and unsuccessful dieters: validity and reliability of the Perceived Self-Regulatory Success in Dieting Scale. Appetite. 2012;58: 822-6.

52. Davis C, Levitan RD, Kaplan AS, Kennedy JL, Carter JC. Food cravings, appetite, and snack-food consumption in response to a psychomotor stimulant drug: The moderating effect of 'food addiction'. Front Psychol. 2014;5(403). doi:10.3389/fpsyg.2014.00403.

53. Moeller FG, Barratt ES, Dougherty DM, Schmitz JM, Swann AC. Psychiatric aspects of impulsivity. Am J Psychiatr. 2001;158:178393.

54. Meule A. Impulsivity and overeating: a closer look at the subscales of the Barratt Impulsiveness Scale. Front Psychol. 2013;4(177):1-4.

55. Reslan S, Saules KK, Greenwald MK, Schuh LM. Substance misuse following Roux-en-Y gastric bypass surgery. Subst Use Misuse. 2014;49:405-17.

56. Meule A. The relation between body mass index and substance use: a true can of worms. Innovations in Clinical Neuroscience. 2014;11(3-4):11-3

57. Davis C. Compulsive overeating as an addictive behavior: overlap between food addiction and Binge Eating Disorder. Curr Obes Rep. 2013;2:171-8.

58. Davis C. From passive overeating to "food addiction": a spectrum of compulsion and severity. ISRN Obes. 2013;2013(435027):1-20.

59. Meule A, Gearhardt AN. Does the revision of substance dependence criteria in DSM-5 have implications for food addiction? submitted.

60. Curtis C, Davis C. A qualitative study of binge eating and obesity from an addiction perspective. Eat Disord. 2014;22:19-32. This was the first study in which the DSM-5 substance use disorder criteria were examined with regard to eating behavior.

61. Weingarten HP, Elston D. Food cravings in a college population. Appetite. 1991;17:167-75. 